\title{
CHRONIC UVEITIS ASSOCIATED WITH PULMONARY TUBERCULOSIS
}

Leandro Diniz Garcia (Universidade José do Rosário Vellano- UNIFENAS, Alfenas, MG, Brasil), Paloma Lilian Andrade Pedroso (Universidade José do Rosário Vellano- UNIFENAS, Alfenas, MG, Brasil), Bianca Rodrigues Mota (Universidade José do Rosário Vellano- UNIFENAS, Alfenas, MG, Brasil), Anna Clara Fachetti Carvalho (Universidade José do Rosário Vellano- UNIFENAS, Alfenas, MG, Brasil), Clara Monteiro Reis (Universidade José do Rosário Vellano- UNIFENAS, Alfenas, MG, Brasil), Rodolfo Pereira Espíndola (Universidade José do Rosário Vellano- UNIFENAS, Alfenas, MG, Brasil)

\section{BACKGROUND}

Tuberculosis continues to be a major health problem worldwide, with Brazil being one of the 22 WHOprioritized countries that concentrate $80 \%$ of the world tuberculosis burden and can affect several organs, with ocular involvement low, with reports that 1 to $3 \%$ of cases of uveitis associated with the tuberculosis bacillus. The objective of this study is to highlight the importance of tuberculosis investigation in patientes with inflamatory ocular alterations, especially in cases of chronic uveitis.

\section{CASE REPORT}

Female patient, 63 years old, nurse, resident in Alfenas MG, with chronic anterior uveitis refractory to immunosuppressive treatment, after long etiological investigation was diagnosed with pulmonary tuberculosis through biopsy in nodular bronchoscopy in right lung apex seen on chest tomography, which evidenced the presence of Koch's bacillus in the pathological anatomy. Although not prevalent, ocular tuberculosis has high morbidity and may evolve with permanent Visual impairment in was cases. Initial ocular complaints and clinical findings are non-specific for the diagnosis, and there is a need to perform complementary exams that are not always sufficient to define it. The most common form, as already mentioned, of ocular involvement is the previous one. The disease may be present even without active systemic disease. The diagnosis can be confirmed if there are laboratory and/or histological Martins by the presence of Mycobacterium tuberculosis.

\section{CONCLUSION}

Ocular tuberculosis is a chronic pleomorphic disease with a high index of visual acuity reduction. Therefore, early treatment increases the chance of maintenance or improvement of this view, it is imperative that the research of this etiology be performed in all patients with chronic uveitis with an indeterminate cause. 